\title{
Research
}

\section{Satisfaction, demand, and opening hours in primary care:}

\author{
an observational study
}

\begin{abstract}
\section{Background}

The ease with which patients can make primary care appointments in the UK has been subject to a pay for performance scheme since 2004. A separate scheme, extended hours - the provision of extra appointments outside normal office hours - was introduced in 2008
\end{abstract}

\section{Aim}

To examine how the provision of additional morning, evening, and weekend appointments influences patient satisfaction with opening hours.

\section{Design and setting}

An observational study in primary care.

\section{Method}

The study collated information on extended hours for all practices in 13 English primary care trusts $(n=639)$. After examining the descriptive statistics the study ran a series of clustered logistic regression models, comparing additional periods of service provision to practice characteristics and to patient satisfaction with access and opening hours in the GP Patient Surveys.

\section{Results}

Practices offering Saturday appointments saw a relative decline in demand for additional hours. Practices offering other time periods did not see this. Satisfaction with opening hours improved slightly for practices offering extra appointments, but was not linked to any time period. The terms and conditions of the extended hours scheme are loosely implemented and this may have limited the apparent effectiveness of the scheme.

\section{Conclusion}

Demand for additional opening in primary care is only influenced by Saturday appointments. Satisfaction with opening hours responds to increased capacity, but is not linked to a specific time period.

\section{Keywords}

health care quality, access, and evaluation; health services accessibility; health services needs and demand; physician's practice patterns; primary health care.

\section{INTRODUCTION}

Accessibility of primary care in the UK has been promoted through a pay for performance scheme since 2004. It has a short but complicated history with many changes in monitoring and financial incentives. ${ }^{1-4}$ Payments were made through the Quality and Outcomes Framework (QOF) and depended on patient satisfaction in the General Practice Patient Survey (GPPS) I between 2008 and 2011. The GPPS is a national postal survey of patient opinion, which has been conducted annually since $2006 .^{5}$

A separate scheme for extended hours commenced in 2008. This enables practices to earn additional income by offering appointments outside the core contracted hours of $8 \mathrm{am}$ to $6.30 \mathrm{pm}$ on weekdays. 'The intended outcome is an increase in patients' access to GPs at times outside current contracted hours, while standards of access and availability during contracted hours are at least maintained." The payments for the extended hours scheme do not depend on patient satisfaction.

An annual payment of $€ 2.95$ per registered patient was available for offering extended hours. This equated to approximately $€ 5600$ of gross annual income per primary care physician..$^{6-9}$ To qualify for the national scheme, practices had to comply with several conditions, listed in Box 1.

Local primary care trusts (PCTs) were given flexibility on how to adopt the national requirements. Uniformity of terms and

CL Morgan, BA (Hons), senior researcher; HJ Beerstecher, artsexamen, GP principal, Canterbury Road Surgery, Sittingbourne, Kent. Address for correspondence

Dr Hendrik J Beerstecher, Canterbury Road Surgery, 111 Canterbury Road, Sittingbourne, Kent, ME10 4JA

E-mail: hendrick.beerstecheranhs.net conditions was also affected by a delay in the issuing of national specifications and many practices agreed a Local Enhanced Service (LES) instead of the national Designated Enhanced Service (DES). The national guidance stated that 'PCTs should particularly assess whether their scheme delivers the same or a broadly similar outcome to that expected from the DES', but there is no report on how closely this has been followed. ${ }^{6}$

Normally a DES obliges PCTs to ensure the service is available to all patients, as is the case with vaccinations and minor surgery. However, for the extended hours DES the minimum target was to engage $50 \%$ of the practices in each PCT. The uptake per PCT is monitored and published by the Department of Health. ${ }^{10,11}$

The hypothesis behind the study was that practices with capacity problems might be more likely to sign up to extended hours, possibly prompted by lower satisfaction survey results. The benefits of the extended hours scheme could be threefold. First, increasing capacity through extended hours generates additional income, where doing so within the core hours does not. Second, survey results for access might improve, generating additional income through the Quality and Outcomes Framework. Third, pressure on core-hours appointments would decrease and this would help the efficiency of the front office.

This report examines how the introduction of the extended hours scheme affected patient opinion and satisfaction in the GP Patient Survey.
Submitted: 30 November 2009; Editor's response: 24 March 2010; final acceptance: 29 June 2010. CBritish Journal of General Practice

This is the full-length article (published online 1 Aug 2011) of an abridged version published in print. Cite this article as: Br J Gen Pract 2011; DOI: 10.3399/bjgp11X588475. 


\section{How this fits in}

There is high satisfaction with opening hours in the UK GP Patient Surveys despite perceived difficulties with access to primary care. Financial incentives to improve access and convenience were introduced in 2004. Offering additional capacity has led to a small relative improvement in patient satisfaction with opening hours. However, only capacity in the form of Saturday appointments reduces patient demand for appointments outside office hours. The extended hours scheme provides a financial incentive to make more appointments available. The scheme rewards practices irrespective of whether patient demand is met. Offering additional appointments does not generate additional income from the Quality and Outcomes Framework, despite Saturday appointments having a small effect on the income generating questions.

\section{METHOD}

\section{Setting}

All English PCTs distributed leaflets titled 'GP services in your area are improving' publicising practices that signed up to the extended hours scheme in December 2008. ${ }^{12,13}$ The study entered the leaflet title string into a search engine (Altavista ${ }^{\mathrm{TM}}$ ) on 3 February 2009. The search identified 13 PCTs providing electronic copies (Table 1). Practices in these PCTs were matched to their national code using the GP lookup file published by the Information Commissioner. ${ }^{14}$ Of the total 639 practices, six could not be matched to both GPPS survey years, for 24 practices the survey did not report all data owing to too few responses, and in 13 practices lunchtime opening was the most requested additional time in 2007-2008, which cannot be provided under the extended hours scheme. For clarity, all analyses are reported after exclusion of practices with missing data leaving 596 (93\%) practices in 13 PCTs.

\section{Type of hours offered}

There are four periods for extended hours: weekdays before 8 am, weekdays after 6.30 pm, Saturday, and Sunday.

Practices listed in the PCT leaflets were retrieved from the NHS Choices website in August 2009 to determine the categories of hours offered. Where NHS Choices did not have a record of the hours offered, either the link provided by NHS choices or GoogleTM were used to find the practice website. For the Google ${ }^{T M}$ search, practice telephone number, practice name and/or practice address strings were entered.

Where neither the NHS Choices nor the practice website displayed the extended hours $(n=124)$ practices were contacted by telephone to verify the category of hours provided. In case of discrepancies, preference was given to telephone verification over the practice website and to practice websites over NHS Choices. Two PCTs specified the hours of participating practices in the leaflet and this information was used instead of the verification process described above.

The control group are practices in the same PCTs that did not offer extended hours.

\section{GP Patient Surveys (GPPS)}

Results of the 2007/2008 patient survey are hosted by the Department of Health. The $2008 / 2009$ patient survey is available from Ipsos Mori. Methodology for both surveys is accessible via the respective websites. ${ }^{15,16}$ Recent publications describe the design and pilot of the 2008/2009 survey, as well as providing analysis of the GPPS and discussion of concerns relating to response bias. ${ }^{17,18}$

The 2008/2009 survey differs from the previous 2007/2008 survey with regard to the number and the wording of questions relating to satisfaction and additional hours (Box 2).

\section{Compliance with national requirements}

The period most requested in the 2007/2008 GPPS was compared to with the period(s) provided by the practice. The requirement was not met if the period in most demand was not provided. The study did not initially collect data on the length of the periods provided and the authors did not want to burden the practices with a second telephone enquiry. These data were complementary and not the focus of the article and the survey for period length was limited to the practices publishing the data on NHS Choices.

\section{Confounding factors}

Age, deprivation, and other patient characteristics can influence questionnaire response rates. ${ }^{17,18}$ In England patient age profile is related to deprivation and practice size (the number of patients registered with the practice). Practice size is, in turn, related to the proportion of physicians who graduated in the UK and total QOF score. Practice size, deprivation, ethnicity, response rate, age and sex all seem to influence patient satisfaction in relation to access and convenience. ${ }^{19-21}$ It seems that 


\section{Box 2. Questions relating to satisfaction and opening hours 2007/2008 \\ 2008/2009}

Over the last 6 months or so, were you satisfied with the hours your GP surgery was open? (yes/no) I was dissatisfied because..

Please tick the ONE box closest to your views:

the surgery was not open early enough in the morning the surgery was not open around lunchtime the surgery was not open late enough in the evening the surgery was not open on a Saturday the surgery was not open on a Sunday or some other reason
How satisfied are you with the hours that your GP surgery or health centre is open? (scale of five) Would you like your GP surgery or health centre to open at additional times?

Which one of the following additional times would you most like the GP surgery or health centre to be open? Please pick one answer showing the time you would most like it to be open:

Before 8 am

At lunchtime

After $6.30 \mathrm{pm}$

On a Saturday

On a Sunday response bias may be a function of population factors, and a more substantial analysis on the intrinsic problems of the GPPS was announced. ${ }^{17,18}$

Since the influence of confounders in the GPPS is not yet fully clarified, the study examined several factors including the average patient postcode Index of Multiple Deprivation and satisfaction (from the 2006/2007 GPPS), practice total QOF score in 2007/2008 (published by the NHS information commissioner) and practice list size (from the 2008/2009 GPPS) in logistic regression models to examine whether practices offering extended hours differ from those that do not. ${ }^{14,15}$ The percentage of UK graduate physicians (taken from the GP research database 2004), and the percentage of patients over 45 years old from the April 2007 Global Sum data (kindly

\section{Table 1. Primary care trust characteristics}

\begin{tabular}{lccc} 
PCT & $\begin{array}{c}\text { Number of practices offering } \\
\text { extended hours (\%) }\end{array}$ & $\begin{array}{c}\text { Number of patients/ } \\
\text { practice, mean (SD) }\end{array}$ & $\begin{array}{c}\text { IMD score, } \\
\text { mean (SD) }\end{array}$ \\
\hline Barnet & $62 / 67(92.5)$ & $5210(3292)$ & $15.6(4.7)$ \\
\hline Bury & $20 / 31(64.5)$ & $6118(2348)$ & $23.4(5.6)$ \\
\hline Darlington & $10 / 11(90.9)$ & $9492(3563)$ & $23.6(6.8)$ \\
\hline East Riding of Yorkshire & $18 / 36(50.0)$ & $8555(4347)$ & $14.6(6.7)$ \\
\hline Hasting and Rother & $22 / 33(66.7)$ & $5347(3327)$ & $24.6(7.8)$ \\
\hline Mid-Essex & $25 / 47(53.2)$ & $7523(4844)$ & $10.3(3.2)$ \\
\hline Norfolk & $58 / 89(65.2)$ & $8065(3963)$ & $16.1(6.3)$ \\
\hline North Tyneside & $19 / 28(67.9)$ & $7055(3178)$ & $25.2(7.9)$ \\
\hline Nottingham City & $43 / 59(72.9)$ & $5264(4075)$ & $40.4(10.0)$ \\
\hline Peterborough & $17 / 23(73.9)$ & $6791(3920)$ & $22.7(7.1)$ \\
\hline Somerset & $43 / 67(64.2)$ & $7654(4382)$ & $15.1(3.5)$ \\
\hline Stoke-on-Trent & $31 / 48(64.6)$ & $5072(3156)$ & $33.3(8.3)$ \\
\hline Wirral & $37 / 57(64.9)$ & $5679(2755)$ & $29.9(12.6)$ \\
\hline Study average & $405 / 596(67.9)$ & $6616(3935)$ & $22.2(11.6)$ \\
\hline National average & $(65.1)^{a}$ & $6547(4009)$ & $23.3(12.8)$
\end{tabular}

November 2008. Data obtained from the 2006/2007 GPPS (IMD) and 2008/2009 GPPS (list size), see confounding factors. provided by the Information Commissioner for the NHS) were used as additional potential confounders. ${ }^{14,22}$

\section{Statistical analyses}

Simple linear regression analysis was used for initial examination of the variables, followed by simple or multiple logistic regression models to compare groups of practices providing different extended hour periods. Logistic regression models were chosen over $t$-tests or ANOVA as the software allows correction for clustering at PCT level while examining dichotomous variables, eliminating a number of relationships of dubious significance. Where there were discrepancies between the simple and multiple logistic regression models, findings were not included in discussion. The analyses were repeated after Box-Cox transformation of the variables to compensate for any skew in the data. Multiple regression models with the transformed variables deviated substantially from simple regression models with the same variables and had too few remaining practices to be reliable. The simple regressions with the transformed variables were not materially different from the untransformed findings.

Statistical analyses were performed using Exce ${ }^{\circledR}$, and Stata (version 7).

\section{RESULTS}

\section{Data constraints}

Initial descriptive and correlation analyses reveal the questionnaire data to be skewed, with $81 \%$ of patients satisfied with opening hours and only $54 \%$ requesting additional opening in 2008/2009. There are strong relationships between patient age profile, deprivation and response rate. The most basic multiple regression model with age profile and deprivation explains $68 \%$ of the variation in the response rate (Appendix 1).

Weak to moderate correlations also existed between the explanatory variables, particularly those of age profile, deprivation, response rate and satisfaction indicators. Demographic and practice variables also relate to satisfaction and demand for opening hours but not significantly to changes in satisfaction or demand (Appendices 2 and 3).

There are a number of national requirements, but compliance with these is variable. Only $37 \%$ of the practices with most requests for Saturday actually provided this period. However, if most patients requested evening appointments, there was a $79 \%$ chance that the practice would provide these. Additionally, only $61 \%$ 
Table 2. National requirement of the Designated Enhanced Service for extended hours

\section{Requirement}

Appointments available to all registered patients

At least 30 minutes per 1000 patients

Periods to match patient preference in GPPS

Periods to match patient preference ${ }^{a}$ : Before 8 am

Periods to match patient preference ${ }^{a}$ : After 6.30 pm

Periods to match patient preference ${ }^{a}$ : On Saturday

Periods to match patient preference ${ }^{a}$ : On Sunday

Period at least 90 minutes in the evening ${ }^{b}$

Period at least 90 minutes Saturday ${ }^{b}$

No concurrent clinics in the extended hours period

No reduction in availability during core hours

Publicised on NHS Choices website (www.nhs.uk)c

a Patient preference is determined by the period with most requests as defined by national requirement.

${ }^{b}$ Assessed for practices specifying duration of period on NHS choices $(n=254)$. ${ }^{c}$ For study group $n=405$.

Proportion of practices

meeting requirement

Not assessed

$207 / 405(51 \%)$

$110 / 139(79 \%$

$106 / 290(37 \%)$

$1 / 1(100 \%)$

$129 / 213(61 \%)$

$71 / 73$ (97\%)

Not assessed

Not assessed

254/405 (63\%)
Not systematically assessed

of the practices providing evening appointments do so in the minimum 90-minute periods required, while $97 \%$ do so on Saturday. Similarly, the requirement to advertise the periods on the NHS website is only met by $63 \%$ of the practices (Table 2 ).

\section{Practices offering any extended hours period}

Patient satisfaction with opening hours declines less for practices that offer extended hours $(-0.87 \%)$ the year after its introduction (2008/2009) compared to those that did not $(-2.31 \%)$. In absolute terms the change is small and may be partly attributable to changes in the questionnaires, declining from $83 \%$ to $82 \%$ of the patients satisfied for practices offering extended hours and $83 \%$ to $81 \%$ for practices that do not offer extended hours. Demand for extra hours declines for Saturday, but increases for Sunday in practices offering any extended hours period (Appendix 4).

Practices that faced higher demand for Sunday opening in the year preceding the extended hours scheme (2007/2008) are more likely to offer any extended hours period. Two other characteristics associated with an increased likelihood to take on the scheme are a younger patient age profile and having more foreign graduate doctors. However, the association of the last two variables is inconsistent, depending whether they are examined individually or in a multiple regression; and it is possible they are affected by multicollinearity, which brings their validity into question (Appendix 4). These findings are not interpreted as sufficient evidence that there are material differences relating to foreign medical graduates or patient age profile.
Practices offering specific extended hours periods

To examine how provision influences demand for specific time periods, the study used the change in demand when the relevant time period was offered. Only demand for Saturday was significantly reduced by Saturday appointments (Table 3). The small effect for evening appointments is not significant in logistic regression models (Appendix 5).

Although practices offering any extended hours period are not materially different from those that do not, larger practices (with more registered patients) are more likely to offer appointments before 8 am and on Saturday. No differences are seen for practices offering evening slots (Appendix 5). Evening appointments were offered preferentially on Monday and Tuesdays (Appendix 6).

Practices offering evening appointments saw a rise in demand for Saturday, while practices offering Saturday saw this fall. Practices offering appointments before 8 am saw an increased demand for Sunday, however this could not be confirmed in a simple logistic regression and this finding is probably not valid (Appendix 5).

\section{DISCUSSION}

\section{Summary}

The extended hours scheme aims to increase the accessibility of primary care. Participation is voluntary, leaving practices to strike a balance between resources and patients demand. This means the scheme has not targeted additional capacity at practices with the highest demand or need. No differences were found between practices that do or do not provide additional capacity, indicating that patient demand and/or satisfaction has not greatly influenced practices' decision to provide extended hours.

Between 2007/2008 and 2008/2009, overall satisfaction with access to appointments declined. The general decline in satisfaction may be attributed to changes in the wording of the questionnaires, but satisfaction declined less for practices participating in the scheme. The absolute difference is small, declining from $83 \%$ to $82 \%$ for practices in the scheme and from $83 \%$ to $81 \%$ for the non-participants. However, the introduction of the extended hours scheme preceded the 2008/2009 questionnaire only by a few months and a greater effect may be seen in future satisfaction surveys.

Under the extended hours scheme, practices had to provide a minimum of two 


\section{Table 3. Change in demand for practices providing various time periods relative to those not providing extended hours}

\begin{tabular}{|c|c|c|c|}
\hline & $\begin{array}{l}\begin{array}{c}\text { Change in demand } \\
\text { for appointments } \\
\text { before } 8 \text { am }\end{array} \\
\text { Relative (absolute) }\end{array}$ & $\begin{array}{c}\text { Change in demand } \\
\text { for appointments } \\
\text { after } 6.30 \mathrm{pm}\end{array}$ & $\begin{array}{c}\begin{array}{c}\text { Change in demand } \\
\text { for appointments } \\
\text { on Saturday }\end{array} \\
\text { Relative (absolute) }\end{array}$ \\
\hline $\begin{array}{l}\text { Not providing extended } \\
\text { hours }(n=191) \\
\end{array}$ & $0 \%(+3 \%)$ & $0 \%(+8 \%)$ & $0 \%(+21 \%)$ \\
\hline $\begin{array}{l}\text { Providing any extended } \\
\text { hours time period ( } n=405 \text { ) }\end{array}$ & $0 \%(+3 \%)$ & $-1 \%(+7 \%)$ & $-2 \%(+19 \%)$ \\
\hline $\begin{array}{l}\text { Providing the relevant time } \\
\text { period ( } n=87,{ }^{\left.\text {a } 313,{ }^{b} 134^{c}\right)}\end{array}$ & $0 \%(+3 \%)$ & $-1 \%(+7 \%)$ & $-4 \%(+17 \%)^{d}$ \\
\hline $\begin{array}{l}\text { Providing extended hours } \\
\text { other than the relevant time } \\
\text { periods }\left(n=318, \text { a } 92,{ }^{\text {b }} 271^{c}\right)\end{array}$ & $0 \%(+3 \%)$ & $0 \%(+8 \%)$ & $-1 \%(+20 \%)$ \\
\hline \multicolumn{4}{|c|}{$\begin{array}{l}\text { Total } 596 \text { practices, } 405 \text { providing extended hours, } 191 \text { do not. Of practices providing requested hours: }{ }^{2} d o \text { so } \\
\text { before } 8 \text { am; }{ }^{b} \text { after } 6.30 \text { pm; and 'on Saturday. Some practices provide additional appointments in more than } \\
\text { one time period resulting in total periods exceeding total practices. Average absolute demand has risen for all } \\
\text { time periods between } 2007 / 2008 \text { and 2008/2009; probably not a true increase, but owing to changes in the } \\
\text { wording and structure of the questionnaires. Relative demand is the value compared to practices not providing } \\
\text { extended hours (first row). 'Only provision of Saturday appointments significantly lowered the relative demand } \\
\text { for Saturday ( } P<0.001) \text {. }\end{array}$} \\
\hline
\end{tabular}

\section{Funding body \\ None.}

\section{Ethics committee}

The study is a service evaluation, performed with publicly available data, which does not relate to individuals. The NRES guidelines indicate for this project no approval was therefore necessary.

\section{Competing interests}

Henrik Beerstecher is a full-time single handed GP who used to do all Saturday morning surgeries between 2001 and 2004. Since 2004 Henrik Beerstecher has not provided services outside core hours nor participated in the extended hours DES. Henrik Beerstecher has no interests for promoting the scheme in any way.

\section{Provenance}

Freely submitted; externally peer reviewed.

\section{Acknowledgements}

We thank the information centre for health and social care, the department of health, and Ipsos Mori for making the data freely available. We thank the reviewers and the editorial team for their valuable contributions and comments, greatly improving this report. We thank family and friends for tolerating and supporting us in the last 5 years.

\section{Discuss this article}

Contribute and read comments about this article on the Discussion Forum: http://www.rcgp.org.uk/bjgp-discuss 15-minute additional appointments per 1000 patients per week, although some may have offered three 10-minute appointments. This is a total of $50-75$ appointments per 1000 patients in the 6 months from the start of the scheme to the 2008/2009 survey. With an average physician consulting rate of 2.9 per patient per annum, 1450 GP appointments would have been taken by 1000 patients; resulting in only $3.4-5.2 \%$ of surveyed patients having direct experience of the additional appointments. ${ }^{23}$ This, and the fact that the questionnaire did not clarify whether patients were aware of their practices offering extended hours, means that it is likely that some of the demand and dissatisfaction expressed in the survey was from patients wanting opening hours that were already available. Additionally, many practices were allowed to offer time periods that were not preferred by most patients, leading to persisting demand or dissatisfaction, further reducing the potential effect of the scheme.

Demand and satisfaction are negatively related, which is expected as patients satisfied with opening hours would not be inclined to ask for additional times. However, there may be subtle differences in the concepts of demand and satisfaction. Demand possibly relates to convenience and satisfaction to capacity.

The link between demand and convenience is illustrated by Saturday appointments. Weekday appointments did not reduce demand for weekday capacity in the same way that Saturday appointments satisfied the demand for Saturday. This indicates it is not just capacity that influences demand, but the convenience of the time period. In the second survey $98 \%$ of the practices experienced most requests for Saturdays, suggesting demand is driven by preference and not by additional capacity per se.

\section{Limitations}

Demand and provision of extended hours. The study could not explain why practices facing increased demand for Sunday opening in the 2007/2008 survey were more likely to offer extended hours in the following year or why the practices that offered extended hours still faced an increased demand for Sunday in the subsequent 2008/2009 survey. However, this might relate to religious or lifestyle values shared by the population and their doctors that determine attitude to unsociable hours.

Additional opening and practice size. The available data do not explain why larger practices are more likely to offer Saturday and early morning weekday appointments. Perhaps physicians that choose to work in larger practices have a different attitude to unsociable hours, or it may be related to the scale of the operation. Offering a Saturday service may be less onerous for a practice with more physicians and front-office staff, where rotation of the unsociable hours would cause less disruption. Equally, if space is a factor, instituting early and late shifts on weekdays may help to increase the efficiency of the existing infrastructure. Further study would be needed to examine the motives that drive practice strategies.

Excluded practices as potential confounders. Data on preference for particular time periods were not released for some practices because there were too few requests from the surveyed patients. If all patients are satisfied with the hours offered and there are no capacity problems then little demand is expected for additional opening. This is reflected in the excluded practices for missing data $(n=24)$, which generally had high satisfaction ratings for access (95\% versus $83 \%$ ). However it is unlikely that this group would have distorted the findings. Within the excluded group, practices offering additional appointments had similar satisfaction ratings to the practices not offering these. Also, the proportion of practices in the group $(n=24)$ that opted to provide additional appointments $(n=14)$ was similar to the 
study group $(n=405$ of 596$)(58 \%$ versus $68 \%)$.

Changes in questionnaires. Questionnaires are not directly comparable from one year to the next, as structure and content are varied. The decline of satisfaction or the increase in demand might be attributable to the changes in the questionnaire, rather than a true absolute change in patient opinion. The study was therefore limited to examining relative variables and practice level changes from one year to the next, comparing the various groups of practices to each other.

Restricting the availability of additional appointments. The study did not systematically examine whether practices made the appointments available for all patients as intended in the national guidelines. The study found statements indicating restrictions for the additional hours for three practices (1\%) advertising the service on the NHS website. However, restricting access to the extra appointments might be more widespread considering the study also encountered this in some practices during the telephone verification for 124 practices. Restricting access to additional appointments might make commercial sense if there is sufficient daytime capacity, the additional appointments generate income, whether they are taken by patients or not. If they are not booked in advance, there would be no requirement for the physician to attend the clinic.

\section{Comparison with existing literature}

Several publications on primary care access reported that satisfaction with opening hours relates to capacity and convenience. These report that satisfaction depends more on convenience than on capacity. However, the patients in the studies were subjected to a discrete choice element: more immediate access (capacity) was offset by a reduction of convenience like lack of appointments that can be booked in advance or choice of practitioner. . $^{2-30}$ The current study differs as the questionnaires do not have a discrete choice element: the capacity was additional and did not reduce convenience. This could explain why increased convenience did not influence satisfaction in this study where it did in the other studies. In keeping with the other publications, the effect of convenience was more overt than for capacity.

\section{Implication for practice and research}

Practices may need to consider their primary aims when redesigning services to improve patient satisfaction or demand. Improving the efficiency of the front office or appointment system may not reduce patient demand for more convenience.

UK incentive schemes for patient access and satisfaction have been subject to several changes in the last 7 years. QOF payments for satisfaction with access have been elusive. It would seem wise for practices to examine the nature of incentive schemes and not to commit to long-term operational changes if funding from temporary incentive schemes is critical to the viability of the service.

In conclusion, patient satisfaction with primary care opening hours responds to an increase in capacity. However, patient demand for additional capacity outside core hours only decreases through the provision of Saturday appointments. A number of limitations make it likely that the small observed effects underestimate the true effect of additional capacity on patient demand and satisfaction.

A further discussion of the study findings and other effects of the extra hours scheme is available on request from the authors. 


\section{REFERENCES}

1. Department of Health. Specification for a directed enhanced service. Access to general medical services. London 2003.

http://www.dh.gov.uk/prod_consum_dh/groups/dh_digitalassets/dadh/den/doc uments/digitalasset/dh_4078734.pdf Referring page:

http://www.dh.gov.uk/en/Healthcare/Primarycare/Primarycarecontracting/GM S/DH_4125637 (accessed 31 Mar 2011).

2. NHS employers. Revisions to the GMS contract 2006/07. London 2006. http://www.nhsemployers.org/SiteCollectionDocuments/Revisions_to_the_GM S_contract_-_full_CD_120209.pdf (accessed 31 Mar 2011).

3. Primary care contracting. Directed Enhanced Service - Access to Primary Care. Practice Plans. London 2006.

http://www.pcc.nhs.uk/uploads/medical/01a_des_access_practice_plan.doc (accessed 31 Mar 2011).

4. Department of health. Variations incorporating the new Directed Enhanced Services. London 2006

http://www.dh.gov.uk/en/Healthcare/Primarycare/Primarycarecontracting/GM S/DH_4138236 laccessed 31 Mar 2011).

5. Department of Health. Statement of Financial Entitlements (SFE). London, 2009

http://www.dh.gov.uk/en/Healthcare/Primarycare/Primarycarecontracting/GM S/DH_4133079 (accessed 31 Mar 2011).

6. Department of Health. Interim guidance Directed Enhanced Service Extended Opening Hours. 18-04-2008, London.

http://www.dh.gov.uk/dr_consum_dh/groups/dh_digitalassets/documents/digi talasset/dh_084332.pdf (accessed 31 Mar 2011).

7. Department of Health. Statement of Financial Entitlements amendment (No 4) directions 2008. London 07-08-2008.

http://www.dh.gov.uk/prod_consum_dh/groups/dh_digitalassets/documents/d igitalasset/dh_087554.pdf (accessed 31 Mar 2011).

8. Primary Care Contracting. Extended hours Access Scheme Directed Enhanced Service FAQs. London 01-09-2008. PCC/PMC/FAQ/Web/010908. http://www.pcc.nhs.uk/uploads/primary_medical/gp_access_extended_hours _des_faqs_i_pb.pdf laccessed 31 Mar 2011).

9. Department of Health. Information relating to estimates of the costs for extended opening of GP practices. Response to freedom of information request. London: Department of Health, 2008.

http://www.dh.gov.uk/en/FreedomOfInformation/Freedomofinformationpublic ationschemefeedback/FOlreleases/DH_090161 (accessed 31 Mar 2011).

10. Department of Health. More surgeries open longer. London: Department of Health, 2008. http://www.dh.gov.uk/en/News/Recentstories/DH_085501 laccessed 31 Mar 2011).

11. Department of Health. GP Extended Opening Hours. November 2008 http://www.dh.gov.uk/prod_consum_dh/groups/dh_digitalassets/dadh/den/doc uments/digitalasset/dh_091677.xls [accessed 31 Mar 2011).

12. Barnet Primary Care Trust. GP services in your area are improving. January 2009. Example of leaflet.

http://www.barnet.nhs.uk/files/trustuploads/gp_access_leaflet_final_page_pe r_view.pdf laccessed 31 Mar 2011).

13. Department of Health. GP data on NHS Choices. London: Department of
Health, 2008

http://www.dh.gov.uk/en/Publicationsandstatistics/Lettersandcirculars/Dearco lleagueletters/DH_091162 (accessed 31 Mar 2011).

114. The Information Centre For Health And Social Care. http://www.ic.nhs.uk/ laccessed 31 Mar 2011).

15. Department of Health. GP patient surveys. London 2009 http://www.dh.gov.uk/en/Publicationsandstatistics/PublishedSurvey/GPpatient survey2007/index.htm (accessed 31 Mar 2011).

16. Ipsos MORI. The GP patient survey. London 2009. http://results.gppatient.co.uk/report/main.aspx (accessed 31 Mar 2011).

17. Campbell J, Smith P, Nissen S, et al. The GP Patient Survey for use in primary care in the National Health Service in the UK - development and psychometric Characteristics. BMC Fam Pract 2009, 10: 57.

18. Roland M, Elliott M, Lyratzopoulos $G$, et al. Reliability of patient responses in pay for performance schemes: analysis of national General Practitioner Patient Survey data in England. BMJ 2009; 339: b3851.

19. Baker R, Bankart M, and Murtagh G. Do the Quality and Outcomes Framework patient experience indicators reward practices that offer improved access? Br J Gen Pract 2009; 59(565): 584-589.

20. Mead N and Roland M. Understanding why some ethnic minority patients evaluate medical care more negatively than white patients. BMJ 2009; 339: b3450.

21. Morgan C, Beerstecher H. What about doctor factors? Letter. BMJ 2009; 339: b4060.

22. The General Practice Research Database. Data relating to 2004, downloaded in April 2007. http://www.gprd.com/home/ laccessed 31 Mar 2011).

23. Hippisley-Cox J and Vinogradova Y. Trends in consultation rates in general practice 1995/1996 to 2008/2009: analysis of the QResearch ${ }^{\circledR}$ database. London, September 2009.

http://www.ic.nhs.uk/webfiles/publications/gp/Trends in Consultation Rates in_General_Practice_1995_96_to_2008_09.pdf laccessed 31 Mar 2011).

24. Sampson F, Pickin M, O'Cathain A, et al. Impact of same-day appointments on patient satisfaction with general practice appointment systems. Br J Gen Pract 2008; 58(544): 641-643.

25. Jewell D. Making general practice fit for the 21 st century. Br J Gen Pract 2005; 55(515): 422-423.

26. Salisbury C, Goodall S, Montgomery AA, et al. Does Advanced Access improve access to primary health care? Questionnaire survey of patients. $\mathrm{Br} J \mathrm{Gen}$ Pract 2007; 57(541): 615-621.

27. Windridge $\mathrm{K}$, Tarrant $\mathrm{C}$, Freeman GK, et al. Problems with a 'target' approach to access in primary care: a qualitative study. Br J Gen Pract 2004; 54(502): 364-366.

28. Rubin G, Bate A, George A, et al. Preferences for access to the GP: a discrete choice experiment. Br J Gen Pract 2006; 56(531): 743-748.

29. Turner D, Tarrant $C$, Windridge $K$, et al. Do patients value continuity of care in general practice? An investigation using stated preference discrete choice experiments. J Health Serv Res Policy 2007; 12(3): 132-137.

30. Gerard K, Salisbury C, Street D, et al. Is fast access to general practice all that should matter? A discrete choice experiment of patients' preferences. $J$ Health Serv Res Policy 2008; 13 Suppl 2: 3-10. 


\begin{tabular}{|c|c|c|c|}
\hline Response rate & $\begin{array}{l}\text { Partial correlation } \\
\text { (Beta) }\end{array}$ & $\begin{array}{c}\text { Significance } \\
(P)\end{array}$ & $\begin{array}{l}\text { Percentage variation } \\
\text { explained by model }\end{array}$ \\
\hline Proportion patients $>45$ years & 0.66 & $<0.001$ & \\
\hline ndex of Multiple Deprivation & -0.27 & $<0.001$ & $68 \%$ \\
\hline
\end{tabular}

Appendix 2. Simple correlations of demographic variables, satisfaction with opening hours, and demand for additional opening hours (study group $n=596$ )

\begin{tabular}{|c|c|c|c|c|c|c|c|c|c|c|}
\hline & $\begin{array}{c}\text { Proportion } \\
\text { satisfied } \\
\text { with opening } \\
\text { hours } \\
2008 / 2009\end{array}$ & $\begin{array}{c}\text { Proportion } \\
\text { want } \\
\text { extra } \\
\text { hours } \\
2008 / 2009\end{array}$ & $\begin{array}{l}\text { Practice } \\
\text { list } \\
\text { size }\end{array}$ & $\begin{array}{c}\text { Index } \\
\text { of } \\
\text { Multiple } \\
\text { Deprivation }\end{array}$ & $\begin{array}{l}\text { Quality } \\
\text { and } \\
\text { Outcomes } \\
\text { Framework } \\
\text { score }\end{array}$ & $\begin{array}{c}\text { Proportion } \\
\text { of patients } \\
>45 \text { years } \\
\text { old } \\
2008 / 2009\end{array}$ & $\begin{array}{c}\text { Proportion } \\
\text { of } \\
\text { graduate } \\
\text { doctors }\end{array}$ & $\begin{array}{l}\text { Change in } \\
\text { satisfaction } \\
\text { with opening } \\
\text { hours } \\
2008 / 08\end{array}$ & $\begin{array}{c}\text { GPPS } \\
\text { response } \\
\text { rate } \\
2007 / 2008\end{array}$ & $\begin{array}{c}\text { GPPS } \\
\text { response } \\
\text { rate } \\
2008 / 2009\end{array}$ \\
\hline Satisfied 2008/2009 & 1.00 & & & & & & & & & \\
\hline Want extra hours 2008/2009 & -0.74 & 1.00 & & & & & & & & \\
\hline practice size & -0.07 & 0.17 & 1.00 & & & & & & & \\
\hline IMD & 0.18 & -0.05 & -0.23 & 1.00 & & & & & & \\
\hline QOF score & 0.10 & 0.00 & 0.21 & -0.11 & 1.00 & & & & & \\
\hline Proportion patient $>45$ years & 0.19 & -0.23 & 0.15 & -0.43 & 0.19 & 1.00 & & & & \\
\hline Proportion UK graduate doctors & 0.02 & 0.02 & 0.31 & -0.31 & 0.16 & 0.32 & 1.00 & & & \\
\hline Change in satisfaction & 0.38 & -0.15 & -0.05 & -0.11 & 0.01 & 0.09 & 0.04 & 1.00 & & \\
\hline Response rate 2007/2008 & 0.19 & -0.20 & 0.26 & -0.62 & 0.28 & 0.83 & 0.40 & 0.10 & 1.00 & \\
\hline Response rate 2008/2009 & 0.20 & -0.20 & 0.28 & -0.58 & 0.27 & 0.79 & 0.39 & 0.09 & 0.91 & 1.00 \\
\hline
\end{tabular}

\section{Appendix 3. Linear multiple regression models of demographic variables, clustered by PCT ( $n=596$ )}

Linear regression: satisfaction

Multiple regression - demographic

Variables $\left(R^{2}=0.13\right) 2008 / 2009$

Practice size

Index of Multiple Deprivation

QOF score

Percentage patients $>45$ years

Coefficient

\begin{tabular}{ccccc} 
Coefficient & Standard error & Beta & $\boldsymbol{P}>\mathbf{z} \mathbf{z}$ & $\mathbf{9 5 \%} \mathbf{C l}$ \\
\hline 0.00 & 0.00 & -0.08 & 0.31 & 0.00 to 0.00 \\
\hline 0.00 & 0.00 & 0.31 & $0.02^{\mathrm{a}}$ & 0.00 to 0.00 \\
\hline 0.00 & 0.00 & 0.08 & 0.08 & 0.00 to 0.00 \\
\hline 0.22 & 0.07 & 0.30 & $0.01^{\mathrm{a}}$ & 0.06 to 0.38 \\
\hline 0.01 & 0.01 & 0.04 & 0.49 & -0.01 to 0.03 \\
\hline 0.57 & 0.07 & & $<0.001$ & 0.41 to 0.74
\end{tabular}

Proportion UK graduate doctors 0.57

0.07

$<0.001$

0.41 to 0.74

Linear regression: satisfaction

Multiple regression - demographic

Variables $\left(R^{2}=0.02\right) 2007 / 2008$ to $2008 / 2009$

Practice size

Index of Multiple Deprivation

QOF score

Percentage patients $>45$ years

Proportion UK graduate doctors

cons

Linear regression: satisfaction

Multiple regression - demographic

Variables $\left(R^{2}=0.12\right) 2008 / 2009$

Coefficient

Standard error

Beta

$P>|z|$

$95 \% \mathrm{Cl}$

Practice size

Index of Multiple Deprivation

0.00

0.00

$-0.09$

0.17

0.00 to 0.00

0.00

0.00

0.03

0.00

$-0.11$

0.15

0.00 to 0.00

0.01

0.00 to 0.00

0.00

0.01

0.02

-0.07 to 0.13

$-0.02$

0.05

0.56

-0.01 to 0.01

-0.13 to 0.10

\section{QOF score}

Percentage patients $>45$ years

9 Coefficien

Standard error

Beta

$P>|z|$

$95 \% \mathrm{Cl}$

Proportion UK graduate doctors

\begin{tabular}{ccccc}
0.00 & 0.00 & 0.19 & $0.02^{\mathrm{a}}$ & 0.00 to 0.00 \\
0.00 & 0.00 & -0.15 & 0.23 & 0.00 to 0.00 \\
0.00 & 0.00 & 0.01 & 0.85 & 0.00 to 0.00 \\
\hline-0.32 & 0.14 & -0.33 & $0.04^{\mathrm{a}}$ & -0.62 to -0.01 \\
\hline 0.00 & 0.01 & 0.01 & 0.79 & -0.02 to 0.03 \\
\hline 0.66 & 0.11 & & $<0.001$ & 0.43 to 0.89 \\
\hline
\end{tabular}

aThese relationships could not be confirmed in simple linear regression models, clustered at PCT level and should be interpreted with caution. The relationships in these models are however compatible with national data, indicating that an older patient profile is associated with lower demand and higher satisfaction (beta -0.35 and 0.30 respectively, $n=77862$ practices). Deprivation is associated with higher satisfaction, but is not related to lower demand, in keeping with national data (beta 0.13 and 0.02 respectively for satisfaction and demand, $\mathrm{n}=7862$ practices). 
Appendix 4. Simple and multiple logistic regression models of provision of Extended hours. Study group, clustered by PCT ( $n=596$, of which 405 providing extended hours)

Logit: providing extended hours (yes/no)

Simple relationships

Satisfaction with hours 07/08

Coefficient Standard error

Want before 8 am 07/08

Want after 6.30 pm 07/08

Want Saturday 07/08

Want Lunchtime 07/08

Want Sunday 07/08

Satisfaction with hours 08/09

$-0.25$

3.43

$13.83 \quad 21.87$

8.72

21.87
9.04

$-6.85$

13.83

91.49

Want extra hours 08/09

Want before am 08/09

Want after 6.30 pm 08/09

Want Saturday 08/09

Want Lunchtime 08/09

3.28

3.28
-2.92

-2.92
12.58

1.35

$-9.77$

3.54

21.87

32.15

$3.50-0.94$

$-0.07$

$P>|z|$

$95 \% \mathrm{CI}$

Want Sunday 08/09

Practice size

Index of Multiple Deprivation

QOF score

Change in satisfaction with opening hours

Percentage patients $>45$ years

Proportion UK graduate doctors

Change in satisfaction for QOF questions

2.99

7.86

3.48

2.16

$\begin{array}{ll}7.02 & 7.25\end{array}$

25.59

7.25
10.37

0.00

0.00

0.01

0.00

7.16

$7.16 \quad 2.85$

0.59

$2.85 \quad 2.51$

$1.70 \quad-2.10$

$\begin{array}{lll}-0.42 & 0.25 & -1.67\end{array}$

$\begin{array}{ccc}-0.42 & 0.25 & -1.67 \\ 1.18 & 0.62 & 1.89\end{array}$

$0.94 \quad-6.97$ to 6.47

$0.53 \quad-29.03$ to 56.70

$0.34 \quad-8.99$ to 26.44

$0.05-13.78$ to 0.08

$0.53 \quad-29.03$ to 56.70

$0.004 \quad 28.48$ to 154.50

QOF points realating to appointments 08/09

0.00

0.01

$-0.84$

0.35

-3.57 to 10.15

-8.78 to 2.93

$\begin{array}{ll}0.11 & -2.84 \text { to } 27.99 \\ 0.70 & -5.48 \text { to } 8.18\end{array}$

Logit: providing extended hours (yes/no)

Multiple regression - explanatory variables

oefficient

Standard error

Satisfaction with opening hours 07/08

z

-14.00 to -5.55

$<0.001$

-7.19 to 21.23

5.26 to 45.92

0.01

0.00 to 0.00

Want before 8 am 07/08

Want after $6.30 \mathrm{pm}$ 07/08

$\begin{array}{lll}2.54 & 3.99 & 0.64 \\ 8.58 & 16.05 & 0.53\end{array}$

-0.00 to 0.02

Want Saturday 07/08

Want Sunday 07/08

Practice size

Index of Multiple Deprivation

$11.64 \quad 6.21$

6.21

$-4.28 \quad 5.38$

$\begin{array}{cc}85.05 & 39.49 \\ 0.00 & 0.00\end{array}$

$39.49-0.80$

$\begin{array}{lll}0.00 & 0.00 & 1.59\end{array}$

$\begin{array}{ll}0.00 & 1.59 \\ 0.01 & 0.11\end{array}$

QOF score 0.00

Percentage patients $>45$ years

$0.00 \quad 0.00$

$-2.24 \quad 2.23$

$\begin{array}{ll}0.00 & 1.03 \\ 2.23 & -1.00\end{array}$

Proportion UK graduate doctors

$-0.40$

$\begin{array}{ll}0.18 & -2.15 \\ 3.75 & -0.92\end{array}$

$\begin{array}{lll}-3.47 & 3.75 & -0.9\end{array}$

0.25

0.00 to 0.01

$\begin{array}{ll}0.20 & 0.00 \text { to } 0.01 \\ 0.01 & 1.58 \text { to } 12.74\end{array}$

$0.04^{\mathrm{a}} \quad-6.89$ to -0.23

\section{Logit: providing extended hours (yes/nol}

Multiple regression - post hoc variables

Satisfaction with opening hours 08/09

Want extra hours

Coefficient Standard error

0.36

-0.91 to 0.07

$0.06 \quad-0.04$ to 2.41

$0.40 \quad-0.01$ to 0.01

Want before 8 am 08/09

Want after $6.30 \mathrm{pm}$ 08/09

Want Saturday 08/09

want lunchtime 08/09

$2.63 \quad 2.94$

$2.94 \quad 0.89$

$-1.00 \quad 4.46$
6.91

$6.91 \quad 8.47$

$2.49 \quad 4.22$

$\begin{array}{ll}-7.78 & 3.65\end{array}$

$1.44 \quad 5.13$

Want Sunday 08/09

1.44

$\begin{array}{ll}1.35 & 10.73\end{array}$

Change in satisfaction with opening hours $\quad 7.50$

Change in satisfaction for QOF questions

QOF points relating to appointments 08/09

0.96

$-0.01$

Significant relationships shown in bold. aProportion of patients over 45 years and graduate doctors are not consistently significant in simple and multiple regressions and

these results should be interpreted with caution. 


\section{Appendix 5. Multiple regression of practice attributes in relation to provision of particular time periods. Practices providing extended hours, clustered by PCT $(n=405)$}

\begin{tabular}{|c|c|c|c|c|c|}
\hline \multicolumn{6}{|l|}{$\begin{array}{l}\text { Logit: providing appointments } \\
\text { Before } 8 \text { am (yes/no) }\end{array}$} \\
\hline \multicolumn{6}{|l|}{ Change in demand for } \\
\hline Period before 8 am & 15.76 & 12.98 & 1.21 & 0.23 & -9.68 to 41.41 \\
\hline Period after $6.30 \mathrm{pm}$ & -3.67 & 4.37 & -0.84 & 0.40 & -12.23 to 4.90 \\
\hline Period Saturday & 0.74 & 3.11 & 0.24 & 0.81 & -5.35 to 6.82 \\
\hline Period Sunday & -13.62 & 6.10 & -2.23 & $0.03^{a}$ & -25.57 to -1.66 \\
\hline Practice size & 0.00 & 0.00 & 2.25 & 0.02 & 0.00 to 0.00 \\
\hline Index of Multiple Deprivation & -0.02 & 0.01 & -1.54 & 0.12 & -0.05 to 0.01 \\
\hline QOF score & 0.00 & 0.00 & 0.09 & 0.93 & -0.01 to 0.01 \\
\hline Change in satisfaction with opening hours & 2.73 & 3.18 & 0.86 & 0.39 & -3.50 to 8.97 \\
\hline Percentage patients $>45$ years & -2.44 & 2.15 & -1.14 & 0.26 & -6.65 to 1.77 \\
\hline Proportion UK graduate doctors & 0.40 & 0.35 & 1.13 & 0.26 & -0.29 to 1.09 \\
\hline Change in satisfaction for QOF questions & 0.71 & 1.16 & 0.62 & 0.54 & -1.55 to 2.98 \\
\hline QOF points realating to appointments 08/09 & 0.00 & 0.01 & 0.28 & 0.78 & -0.01 to 0.01 \\
\hline cons & -1.20 & 2.61 & -0.46 & 0.65 & -6.31 to 3.91 \\
\hline \multicolumn{6}{|l|}{ Logit: providing appointments } \\
\hline \multicolumn{6}{|l|}{ After 6.30 pm (yes/no) } \\
\hline Multiple regression & Coefficient & Standard error & $\mathbf{z}$ & $P>|z|$ & $95 \% \mathrm{Cl}$ \\
\hline \multicolumn{6}{|l|}{ Change in demand for } \\
\hline Period before 8 am & -5.44 & 12.01 & -0.45 & 0.65 & -28.99 to 18.10 \\
\hline Period after $6.30 \mathrm{pm}$ & -4.61 & 5.08 & -0.91 & 0.37 & -14.57 to 5.36 \\
\hline Period Saturday & 13.97 & 1.41 & 9.88 & $<0.001$ & 11.19 to 16.74 \\
\hline Period Sunday & 1.15 & 4.29 & 0.27 & 0.79 & -7.26 to 9.56 \\
\hline Practice size & 0.00 & 0.00 & -0.39 & 0.70 & 0.00 to 0.00 \\
\hline Index of Multiple Deprivation & 0.00 & 0.01 & -0.30 & 0.77 & -0.03 to 0.02 \\
\hline QOF score & 0.00 & 0.00 & -0.68 & 0.50 & -0.01 to 0.00 \\
\hline Change in satisfaction with opening hours & -3.30 & 3.44 & -0.96 & 0.34 & -10.04 to 3.44 \\
\hline Percentage patients $>45$ years & -2.90 & 1.95 & -1.49 & 0.14 & -6.72 to 0.92 \\
\hline Proportion UK graduate doctors & -2.00 & 0.36 & -1.18 & 0.24 & -1.13 to 0.28 \\
\hline Change in satisfaction for QOF questions & 0.71 & 1.06 & -1.89 & 0.06 & -4.07 to 0.08 \\
\hline QOF points realating to appointments 08/09 & 0.00 & 0.01 & 0.22 & 0.83 & -0.02 to 0.03 \\
\hline cons & 3.23 & 3.82 & 0.85 & 0.40 & -4.26 to 10.73 \\
\hline \multicolumn{6}{|l|}{ Logit: providing appointments } \\
\hline \multicolumn{6}{|l|}{ On Saturdays (yes/no) } \\
\hline Multiple regression & Coefficient & Standard error & $\mathbf{z}$ & $P>|z|$ & $95 \% \mathrm{Cl}$ \\
\hline \multicolumn{6}{|l|}{ Change in demand for } \\
\hline Period before 8 am & -15.71 & 9.96 & -1.58 & 0.12 & -35.24 to 3.81 \\
\hline Period after $6.30 \mathrm{pm}$ & 3.65 & 4.11 & 0.89 & 0.37 & -4.40 to 11.70 \\
\hline Period Saturday & -16.74 & 2.85 & -5.87 & $<0.001$ & 11.19 to 16.74 \\
\hline Period Sunday & 4.30 & 13.12 & 0.33 & 0.74 & -21.42 to 30.03 \\
\hline Practice size & 0.00 & 0.00 & 5.49 & $<0.001$ & 0.00 to 0.00 \\
\hline Index of Multiple Deprivation & 0.01 & 0.01 & 0.90 & 0.37 & -0.01 to 0.02 \\
\hline QOF score & 0.00 & 0.00 & -0.77 & 0.44 & -0.01 to 0.00 \\
\hline Change in satisfaction with opening hours & 1.39 & 3.55 & 0.39 & 0.70 & -5.57 to 8.36 \\
\hline Percentage patients $>45$ years & 4.68 & 3.10 & 1.51 & 0.13 & -1.41 to 10.76 \\
\hline Proportion UK graduate doctors & -0.50 & 0.51 & -0.98 & 0.33 & -1.49 to 0.49 \\
\hline Change in satisfaction for QOF questions & 2.28 & 0.94 & 2.42 & 0.02 & 0.43 to 4.12 \\
\hline QOF points realating to appointments $08 / 09$ & 0.00 & 0.01 & -0.02 & 0.98 & -0.02 to 0.02 \\
\hline cons & 0.71 & 2.92 & 0.24 & 0.81 & -5.00 to 6.43 \\
\hline
\end{tabular}

